\title{
Formació del professorat per a la innovació basada en la pràctica reflexiva
}

\author{
Glòria Borràs Perelló, IES Eugeni d'Ors, L'Hospitalet de Llobregat \\ Inés Fez Contreras, IES Margarida Xirgu, L'Hospitalet de Llobregat \\ Joan Aliberas Maymí, IES Josep Puig i Cadafalch, Mataró \\ Josi Mirandes Grabolosa, IES Príncep de Viana, Barcelona \\ Maria Lloret Llorca, IES Eugeni d'Ors, L'Hospitalet de Llobregat \\ Miquel Nistal Fernandez, IES St. Josep de Calassanç, Barcelona, mnistal@xtec.cat
}

Durant dos cursos els autors hem format part, com a formadors o com a participants, d'un seminari de formació del professorat de ciències per la innovació, basat en la pràctica reflexiva. La finalitat era potenciar innovacions en la pràctica docent, en línia amb les concepcions actualment vigents en la didàctica de les ciències. És el moment de fer-ne balanç.

Paraules clau: formació permanent, professorat de ciències, pràctica reflexiva, comunitat d'aprenentatge, innovació docent, cicle reflexiu.

Després de gairebé dos cursos, dos formadors (Miquel i Joan) i algunes de les professores que hi hem participat tots dos cursos (Glòria, Maria i Inés en grup i Josi individualment) hem volgut fer un petit balanç del que ha significat per a nosaltres. El que escrivim és el resum d'algunes converses.

Glòria, Maria i Inés:

\section{canviar la manera de fer classe}

\section{Ells ho poden fer}

Quan et diuen "profe, no ho sé!" els contesto "jo tampoc" i es queden parats. Els demano que facin una predicció, que diguin què passarà... Es tracta de plantejar-ho de forma que vegin que efectivament alguna cosa en saben. I llavors diuen "ah, sí que ho sé!" i tiren endavant. Ha canviat el meu paper, l'altre dia ho parlava amb els alumnes: "no es tracta que jo dirigeixi, sinó d'acompanyar-vos en la vostra tasca". Fer que expliquin el que pensen; totes les idees tenen coses aprofitables. Quan no lliguen amb les de la ciència he d'ajudar-los a revisar-les.

\section{Escriure}

A classe ara hi ha més participació de l'alumnat i menys explicació. El que costa més és que escriguin, que donin forma escrita al que ja saben.

De fet, aquest és un problema que també tenim nosaltres. Quan en el seminari ens demanen que escrivim el que pesem de determinada cosa, ens costa molt donar l'opinió, trobar les paraules. Escriure-ho és molt més difícil que dir-ho. T'adones que l'escrit de vegades es pot interpretar d'una altra manera; llavors l'has de refer, fer-lo més precís. A més, oralment es transmet més informació, és més càlid. Per això costa molt parar-te a reflexionar.

\section{Costos i beneficis}

Costa reflexionar i costa força temps fer una nova seqüència. Però això no vol dir que tot sigui negatiu: al contrari, tot ho compensa el portar-ho a la pràctica i veure que et satisfà, així com aprofitar idees, activitats o estratègies dels companys. I sobretot, fa il.lusió notar que estàs, amb els companys, en un procés de canvi que t'ajuda a millorar com a professional i a estar més de gust a l'aula.

A més, venir al seminari serveix de teràpia. Et sents més acompanyada. És la manera de poder 
innovar, perquè tota sola no ho pots fer. S'han de provar les coses una per una, amb paciència, amb una base més sòlida que anteriorment, i sobretot amb la reflexió i l'intercanvi que proporcionen aquests seminaris.

\section{Els companys del centre}

Al meu centre, com que vam fer el projecte "Ciències 12-16" (Izquierdo i al., 1994-98), compartim una mateixa filosofia de fons. Per això no tenim problemes entre nosaltres. Tenim clar que el temari no ho és tot, que hi ha coses més importants com l'autoestima de l'alumnat a l'hora d'aprendre o que el que s'aprengui quedi prou sòlid i se sàpiga fer servir. El temps no ens hauria de preocupar.

Però també hi ha companys de centre que no estan en aquesta línia. El material que elaborem no els serveix, perquè no entenen el seu sentit. Qui no ho veu, no ho veu. Llavors no veuen la necessitat de canviar. Hi ha gent que no en vol saber res, però altres t'escolten i voldrien venir si poguessin.

\section{osi: \\ la forma de mirar i la por}

\section{Pràctica i reflexió}

Les sessions de formació del curs passat i les que portem d'aquest m'han servit per connectar més estretament la teoria (el que crec que hauria de fer) i la meva pràctica real, recorrent el pont entre teoria i pràctica, en tots dos sentits, una vegada i una altra. El que fem i parlem en el curs ho faig pensant en la classe que he fet avui i en la que faré demà, una mica millor.

Per a mi el curs és un espai de temps per aturar-me a fer autoreflexió. Com que l'activitat del dia a dia no em deixa prou espai per fer-ho -ni em surt si ho intento tota sola- tendeixo a mantenir les formes d'actuació, encara que no n'estigui gaire convençuda.

\section{El model de persona}

El que va ser decisiu per a mi va ser un article (Aliberas, 2008) que ens van passar: vaig trobar que el que allà es volia aconseguir era el mateix que jo sempre havia volgut aconseguir a l'aula. Em permet connectar el meu jo-persona amb el meu jo-professora. Hi vaig veure no només una reflexió didàctica, sinó que partia d'una determinada concepció de persona, una concepció de persona que m'interessa perquè inclou l'aspecte emocional. No es limita únicament als aspectes cognitius, com massa sovint passa en didàctica.

Es nota que els formadors són professors en actiu, vinculats a l'aula real, dia a dia. No venen amb el missatge implícit que ells tenen "la veritat". Tot plegat em transmet confiança.

\section{La manera de mirar l'alumnat}

Un dels resultats més rellevants per a mi de participar en el seminari ha estat veure clarament que si jo actuo diferent amb l'alumnat, ells aprenen diferent, que sóc una variable fonamental en el seu procés. Que no és veritat, com de vegades ens sembla, que l'alumnat sigui l'única variable que expliqui el seu propi èxit o fracàs. El discurs tòpic de part del professorat és que les classes no funcionen perquè els alumnes... (són immigrants? estan poc motivats? tenen poca base?...). Que la culpa és d'ells. És l'excusa perfecta per no fer-hi res. Però si hi volem fer alguna cosa cal pensar que el nostre paper és decisiu en la marxa de la classe, que la nostra mirada condiciona: si els miro diferent, actuo diferent i aprenen diferent. Mirar tots els alumnes amb confiança els transmet confiança en les seves possibilitats. Les expectatives són profecies que s'acaben complint.

\section{Innovar}

Ara sembla que innovar sigui introduir les TIC a l'aula. Per a mi la veritable innovació és anar conduint les classes en funció del progrés dels alumnes, i no del que va marcant el programa o el llibre. Busco que siguin capaços de fer inferències sobre coses reals i properes.

Però això m'ha ocasionat contradiccions. Sempre he estat defensora del treball en equip del professorat, que hem de treballar plegats, però ara que veig la necessitat -i les ganes!- de fer coses noves, això no em permet ser prou conseqüent amb mi mateixa ja que no tothom evoluciona al mateix ritme ni en la mateixa direcció i es fa difícil avançar com a equip.

\section{La por al que no és conegut}

Un altre aspecte que vull comentar és el de la por: la por associada a deixar la seguretat d'unes maneres de fer acceptades per tothom per aventurar-me en situacions noves, que crec millors, però que no conec bé ni domino prou. És la sensació d'angúnia quan fas un salt en el buit sense saber si allà on vas a parar serà prou sòlid com per justificar el risc. El grup de formació m'ajuda a superar aquesta por al compartir la necessitat del canvi amb companys i companyes i al comptar, també, amb el suport dels formadors.

\section{El canvis}

El primer any em va ajudar a allunyar-me de la seqüència tradicional de cada tema de física i química per plantejar la classe com un suport al procés de l'alumne, utilitzant com a eina el cicle d'a- 
prenentatge. El segon any m'ha servit més per concretar què és important que aprenguin, quin tipus d'inferències haurien de ser capaços de fer, amb autonomia, en la seva vida quotidiana.

La teoria ja la tenia clara per formacions anteriors, però ara amb el seminari he pogut centrar-me en canviar la meva acció a l'aula. És com si estigués legalitzant una part de mi.

Un dels canvis que he anat introduint té relació amb les preguntes de l'alumnat. Ara els torno les preguntes en comptes de respondre-les, potser reformulant-les una mica, perquè confio que les poden respondre. Si no hi confies, llavors fas de "mare nutrícia": ells demanen i tu dones. Però llavors els mantens lligats, depenen de tu.

\section{Miquel i J oan: ajudar a canviar}

\section{Un mètode: la pràctica reflexiva}

Aquest mètode fa servir l'autoanàlisi per ajudar els participants a partir de les seves concepcions sobre la pròpia pràctica per millorar-les.

La introducció de noves idees permet contrastales amb les pròpies i explorar els canvis que impliquen en la pràctica, avançant cap a projectes personals d'innovació a l'aula. I quan es porten a terme, és important observar i recollir evidències dels canvis produïts per treure'n conclusions per a la vegada següent.

Tot el procés es basa en l'ús de tècniques grupals per fomentar la verbalització dels participants, el contrast d'idees i recollir totes les aportacions. D'aquesta manera es va fent la construcció col.lectiva de coneixement, un coneixement que és a la vegada teòric i pràctic. Els formadors en tot el procés fan més d'acompanyants que de directors.

Alguns professors participants ens han manifestat que algunes de les tècniques utilitzades en el seminari els han servit a l'aula, un altre àmbit on es construeix coneixement col-lectivament.

\section{Un objectiu: la innovació a l'aula}

Al final de cada cicle reflexiu (acció - reflexió nova acció) se'n pot començar un altre partint de les evidències dels canvis produïts a l'aula. És molt positiu constatar la satisfacció amb què els participants valoren, en general, la nova situació que s'ha produït a l'aula, les innovacions que hi han pogut realitzar malgrat les dificultats que hi han trobat.

\section{Una fita: la comunitat d'aprenentatge}

L'objectiu darrer dels seminaris d'innovació en ciències $(\mathrm{SIC})$ és convertir el grup de professorat assistent en una autèntica comunitat d'aprenentatge on tots els integrants -participants i formadors- interaccionen en la construcció col-lectiva de coneixement.

Les dues primeres sessions dels seminaris són bàsiques en la constitució i cohesió del grup que s'ha de convertir en comunitat d'aprenentatge crític i compartit. Ajuden a crear una atmosfera de confiança dins del grup. Al llarg de les sessions es pot veure que la majoria es va involucrant activament en una manera de fer, de parlar, de compartir problemes reals, participant en un procés de debat organitzat que no és habitual en els nostres centres.

De mica en mica el grup pot gestionar-se ell mateix cada vegada amb més autonomia.

\section{Una experiència enriquidora}

Per als formadors, l'ús de la metodologia basada en la pràctica reflexiva dóna lloc a unes relacions humanes més intenses i productives. El fet que tothom pugui partir de la seva pràctica docent per millorar-ne aspectes significatius facilita la implicació del professorat en la tasca.

Tothom aprèn de tothom. Els formadors aprenem de la mateixa manera que ho fa la resta de membres del grup, amb debats intensos. Aportem, però també rebem. El fet que els formadors siguem alhora professors en actiu apropa la nostra realitat a la de la resta dels professors i ens permet compartir força dels problemes, neguits i entrebancs que ens han anat sorgint.

Les múltiples reunions de preparació, l'ús interactiu del moodle i el fet de constituir una gran comunitat d'aprenentatge amb la resta de formadors en ciències, proporcionen unes relacions professionals i humanes enriquidores i molt valuoses.

L'aprenentatge en comú i la constitució d'un autèntic equip de formadors són una experiència professional molt gratificant. Com també ho és haver treballat amb un col-lectiu de professores i professors que volien millorar les seves classes i haverlos ajudat a aconseguir-ho.

En aquests moments tan crítics per a l'educació al nostre país, és una bona notícia haver aconseguit introduir innovacions a l'aula que fan més satisfactori el treball del professorat i de l'alumnat.

Una via que no s'hauria d'abandonar.

\section{Bibliografia}

Aliberas, J. (2008). Ensenyar ciències a l'ESO. Ciències, 9, p. 28-34.

Izquierdo i al. (1994-98). Projecte "Ciències 12-16". Barcelona: Departament d'Ensenyament. 